\title{
Ion beam shaping of Au nanoparticles in silica: Particle size and concentration dependence
}

\author{
E. A. Dawi, ${ }^{1}{ }^{1, a)}$ G. Rizza, ${ }^{2}$ M. P. Mink, ${ }^{1}$ A. M. Vredenberg, ${ }^{1}$ and F. H. P. M. Habraken ${ }^{1}$ \\ ${ }^{1}$ Debye Institute for Nanomaterials, Nanophotonics Section, Utrecht University, P.O. Box 80000, \\ 3508 TA Utrecht, The Netherlands \\ ${ }^{2}$ Ecole Polytechnique, Laboratoire des Solides Irradiés, DSM/IRAMIS-CNRS, 91128 Palaiseau Cedex, \\ France
}

(Received 21 October 2008; accepted 16 February 2009; published online 3 April 2009)

\begin{abstract}
Irradiation with swift heavy ions of spherical Au nanoparticles confined within a silica matrix shapes them into prolate nanorods and nanowires whose principal axes are aligned along the beam direction. In the present paper, we investigate the role that is played by the initial nanoparticle size and concentration in this so-called ion-shaping mechanism. We have produced silica films wherein Au nanoparticles with average diameters of 15, 30, and $45 \mathrm{~nm}$ were embedded within a single plane and have irradiated these films at $300 \mathrm{~K}$ at normal incidence with 18,25 , and $54 \mathrm{MeV} \mathrm{Ag}$ ions. We demonstrate the existence of both threshold and saturation fluences for the elongation effects mentioned. The values of these critical fluences depend both on the ion energy and the initial nanoparticle size. Moreover, we show that $45 \mathrm{~nm} \mathrm{Au}$ particles are not deformed when irradiated with $18 \mathrm{MeV} \mathrm{Ag}$ ions, such that this value corresponds to an energy threshold for the deformation process. As far as the influence of the nanoparticle concentration on the shaping characteristics is concerned, we have found that above the critical irradiation fluence, the deformation effect becomes very sensitive to the initial concentration of the nanoparticles. (C) 2009 American Institute of Physics. [DOI: 10.1063/1.3103267]
\end{abstract}

\section{INTRODUCTION}

Metallic nanoparticles (NPs) are currently receiving broad scientific and technological interest because some of their specific physical properties are different from those of the corresponding bulk material. ${ }^{1,2}$ In particular, when light impinges onto a metallic NP, its free conduction electrons may respond collectively by oscillating in resonance. This collective resonant excitation, which occurs in the visible range of the electromagnetic spectrum, is known as a surface plasmon resonance (SPR). The SPR peak depends on the size, the shape, and the chemical environment of the metal $\mathrm{NP}$, such that modifying one of these parameters represents a way to control the optical properties of the corresponding composite materials (i.e., a matrix containing metallic NPs).

One of the interesting aspects is the possibility of shifting the SPR peak of metal NPs into the infrared region by modifying their aspect ratio. ${ }^{3}$ The ion beam shaping technique is becoming, in this respect, a powerful tool to manipulate matter at the nanometer scale. It allows us to transform spherical dielectric particles into oblate nanostructures, i.e., with their elongation normal to the beam direction, and metal NPs confined within a dielectric matrix into prolate nanorods and nanowires with their elongation along the beam direction. The latter point is of particular interest because the fabrication of composite glasses with unique properties is one of the key issues in the field of optical devices, with applications in photonics and plasmonics. ${ }^{4}$

The possibility of growing nanorods and nanowires from spherical Co NPs embedded in silica by using high-energy

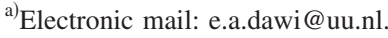

ions (200 MeV I) was first reported by D'Orléans et al. ${ }^{5-7}$ Two deformation regimes have been observed: (i) At low fluences, the irradiation induces a fragmentation of the smaller NPs and an elongation of the larger NPs into nanorods. (ii) At higher fluences these nanorods grow into nanowires, likely at the expense of smaller nanostructures. Giulian et al. ${ }^{8}$ studied the effect of swift heavy-ion irradiation on polydisperse Pt NPs with a diameter in the range of 3-15 nm within a $\mathrm{SiO}_{2}$ matrix. These authors showed that NPs smaller than an energy dependent threshold diameter $(\sim 7 \mathrm{~nm})$ do not change in shape, but their diameter decreases in size with increasing irradiation fluence until they are dissolved into the silica matrix. On the other hand, Giulian et al. ${ }^{9}$ reported that Pt NPs with a diameter above the threshold value become progressively elongated with increasing fluence, with the length of the smaller axis saturating at approximately this threshold value. Olivier et al. ${ }^{10}$ investigated the ion-shaping mechanism for embedded Ag NPs. Penninkhof et al. ${ }^{11}$ investigated the ion-shaping of $\mathrm{Au}$ NPs confined within a planar silica matrix under irradiation with $30 \mathrm{MeV}$ Si ions. A clear deformation of the Au NPs was observed under irradiations for fluences up to $\sim 1$ $\times 10^{15}$ ions $/ \mathrm{cm}^{2}$. Similar results have been obtained by Mishra et al. ${ }^{12}$ in irradiations with $120 \mathrm{MeV} \mathrm{Au}$ ions. A detailed investigation of the irradiation-induced deformation has been carried out by Polman's group for NPs with a hybrid structure, viz., a Au-core/silica-shell ( $\mathrm{Au} @ \mathrm{SiO}_{2}$ ) system. ${ }^{13-15}$ The authors observed that during irradiation with $\mathrm{MeV}$ ions (4-30 MeV), the silica shell turns into an oblate ellipsoidal shape with its main axis perpendicular to the beam direction, while the Au core elongates along the ion beam, provided the silica-shell thickness is large enough 


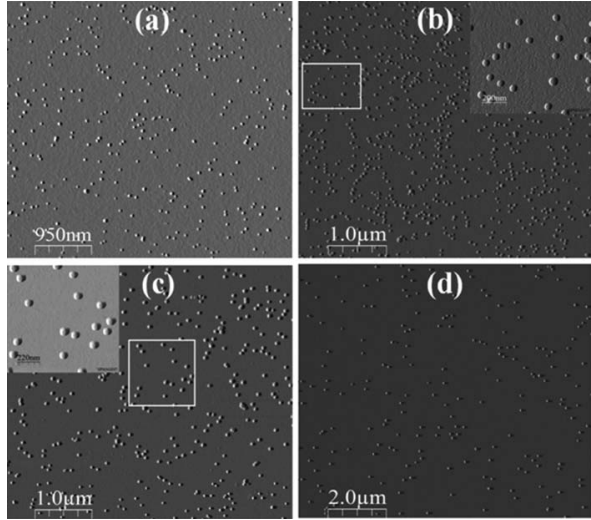

FIG. 1. AFM images of Au NPs distributed on the $\mathrm{SiO}_{2}$ surface after immersion into a solution containing $15 \mathrm{~nm}$ NPs for (a) $5 \mathrm{~min}$ and (b) $40 \mathrm{~min}$ and into solutions containing (c) $30 \mathrm{~nm}$ and (d) $45 \mathrm{~nm}$ NPs for $40 \mathrm{~min}$.

$(>20 \mathrm{~nm})$. This indicates that the deformation of the metal core is somehow related to ion-induced effects in the silica shell.

Although irradiation-induced deformations of NPs have been several times observed and reported in the literature, the mechanism governing this process is still unclear even though a few theoretical studies have been attempted. These are mainly based on the thermal spike model, and the deformation is attributed to irradiation effects either in the metal particle or in the silica matrix. ${ }^{16,17}$ But many questions have remained unanswered, and there is a need for a more systematical investigation of the role played by the initial configuration of the NP and the irradiation parameters. Here we report a systematic and comprehensive experimental investigation of the influence of the NP size (15-45 nm), concentration $\left(10^{8}-10^{10}\right.$ particles $\left./ \mathrm{cm}^{2}\right)$, and ion energy (18-54 $\mathrm{MeV} \mathrm{Ag}$ ions) on the process of ion-induced elongation of spherical Au NPs that are embedded within a silica matrix within a single plane parallel to the surface.

\section{EXPERIMENTAL}

Charge-stabilized monodisperse spherical colloidal gold NPs with average diameters of 15,30 , and $45 \mathrm{~nm}$ were deposited on the surface of oxidized silicon substrates. ${ }^{18}$ The thickness of the thermally grown oxide layer is about 200 $\mathrm{nm}$. For more details about the $\mathrm{Au}$ deposition method, the reader is referred to the literature. ${ }^{19-21}$ The surface density of

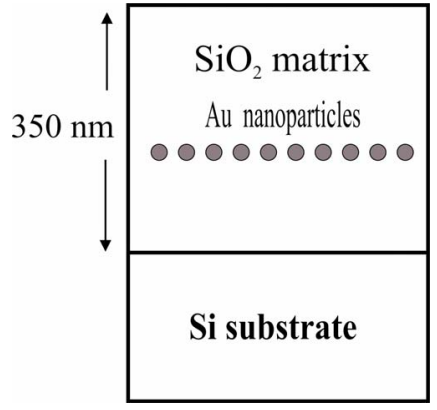

FIG. 2. (Color online) Schematic of the embedded spherical Au NPs within a silica matrix. All NPs are in a plane $150 \mathrm{~nm}$ from the surface of silica matrix.

the Au NPs was monitored by adjusting the immersion time of the sample into the Au NP containing solution between 5 and $40 \mathrm{~min}$. When necessary, a diluted Au solution was used. Atomic force microscopy (AFM) images taken immediately after Au deposition show the uniformity of the Au NP distribution over the surface of the sample (Fig. 1). The surface density of the NPs ranges between $10^{8}$ and $10^{10}$ particles $/ \mathrm{cm}^{2}$. These values correspond to an average distance between the NPs ranging from 50 to $500 \mathrm{~nm}$. The diameters of the attached Au NPs as deduced from AFM images are 15, 30, and $45 \mathrm{~nm}$, respectively. The dispersion amounts to more or less $3 \mathrm{~nm}$. A covering silicon-dioxide layer with a thickness of $150 \mathrm{~nm}$ was then reactively sputtered on top of the $\mathrm{SiO}_{2}$ / Au NPs structure, confining the NPs this way within a sandwich of silica matrix. Finally, the samples were annealed at $900{ }^{\circ} \mathrm{C}$ in an open furnace for 15 min. The AFM images of the surface, taken after deposition of the second oxide and annealing, appear featureless. This indicates that the presence of the NPs at the depth of about $150 \mathrm{~nm}$ in the oxide bilayer does not give rise to protrusions on the surface. Figure 2 provides a schematic illustration of the sample structure.

The samples were irradiated at one of the beam lines at the 6.5 MV EN Tandem accelerator of the University of Utrecht (The Netherlands). Beams of $18 \mathrm{MeV} \mathrm{Ag}^{+4}, 25 \mathrm{MeV}$ $\mathrm{Ag}^{+5}$, and $54 \mathrm{MeV} \mathrm{Ag}^{+8}$ were applied at normal incidence for fluences ranging from $10^{13}$ up to several $10^{14}$ ions $/ \mathrm{cm}^{2}$. Irradiations were performed at room temperature $(300 \mathrm{~K})$, and it has been checked that the beam currents were sufficiently stable during irradiation by measuring them on a spot of $1 \mathrm{~mm}^{2}$ using a micrometer-sized Faraday cup. To avoid

TABLE I. For each immersion time of the sample into the solution containing the Au NPs $(5,10,20,30$, and $40 \mathrm{~min}$ ) for each NP size $(15,30$, and $45 \mathrm{~nm})$, the table reports the surface density as well as the average distance among the NPs.

\begin{tabular}{lccccc}
$\begin{array}{l}\text { Deposition time }( \pm 1 \mathrm{~min}) \\
15 \mathrm{~nm} \mathrm{Au} \text { particle concentration } \\
\left(\text { particles } / \mathrm{cm}^{2}\right)( \pm 10 \%)\end{array}$ & $5 \mathrm{~min}$ & $10 \mathrm{~min}$ & $20 \mathrm{~min}$ & $30 \mathrm{~min}$ & $40 \mathrm{~min}$ \\
$\begin{array}{l}\text { Interparticle distance }( \pm 10 \mathrm{~nm}) \\
30 \mathrm{~nm} \text { Au particle concentration }\end{array}$ & $2.5 \times 10^{9}$ & $7.5 \times 10^{9}$ & $1.4 \times 10^{10}$ & $1.7 \times 10^{10}$ & $4.0 \times 10^{10}$ \\
$\left(\right.$ particles $\left./ \mathrm{cm}^{2}\right)( \pm 10 \%)$ & 115 & 85 & 76 & 50 \\
$\begin{array}{l}\text { Interparticle distance }( \pm 10 \mathrm{~nm}) \\
45 \mathrm{~nm} \mathrm{Au} \mathrm{particle} \mathrm{concentration}\end{array}$ & $\ldots$ & $9.0 \times 10^{8}$ & $2.3 \times 10^{9}$ & $2.8 \times 10^{9}$ & $3.2 \times 10^{9}$ \\
$\left(\right.$ particles $\left./ \mathrm{cm}^{2}\right)( \pm 10 \%)$ & $\ldots$ & 433 & 208 & 188 & 176 \\
Interparticle distance $( \pm 10 \mathrm{~nm})$ & $\ldots$ & 471 & $\ldots$ & $9.0 \times 10^{8}$ & $1.0 \times 10^{9}$ \\
\hline \hline
\end{tabular}


TABLE II. Values for electronic $\left(S_{e}\right)$ and nuclear $\left(S_{n}\right)$ stopping power for $\mathrm{SiO}_{2}$ and gold and projected range $\left(R_{p}\right)$ obtained for the applied ion beams $(15,25$, and $54 \mathrm{MeV} \mathrm{Ag}$ ions). All the values are obtained using the code SRIM 2008 (Ref. 22).

\begin{tabular}{lccccc}
\hline \hline & $\begin{array}{c}S_{e}\left(\mathrm{SiO}_{2}\right) \\
(\mathrm{keV} / \mathrm{nm})\end{array}$ & $\begin{array}{c}S_{n}\left(\mathrm{SiO}_{2}\right) \\
(\mathrm{keV} / \mathrm{nm})\end{array}$ & $\begin{array}{c}S_{e}(\mathrm{Au}) \\
(\mathrm{keV} / \mathrm{nm})\end{array}$ & $\begin{array}{c}S_{n}(\mathrm{Au}) \\
(\mathrm{keV} / \mathrm{nm})\end{array}$ & $\begin{array}{c}R_{p} \\
(\mu \mathrm{m})\end{array}$ \\
\hline $18 \mathrm{MeV} \mathrm{Ag}{ }^{+4}$ & 5.4 & 0.23 & 11 & 0.9 & 5.8 \\
$25 \mathrm{MeV} \mathrm{Ag}$ & 6.7 & 0.18 & 14 & 0.7 & 6.9 \\
$54 \mathrm{MeV} \mathrm{Ag}$ & 9.7 & 0.10 & 24 & 0.4 & 10.3 \\
\hline \hline
\end{tabular}

sample damage by heating during the irradiation, the samples were mounted on a massive metallic holder using a conductive paste. The beam was swept electrostatically in order to obtain a homogeneous irradiation over the entire sample area of $2 \times 2 \mathrm{~cm}^{2}$. At the energies applied, the values for the projected ranges of the silver ions in $\mathrm{SiO}_{2}$, as deduced from the SRIM 2008 code, $^{22}$ are 5.8, 6.9, and $10.3 \mu \mathrm{m}$, respectively. These projected ranges are much larger than the thickness of the oxide layers containing the metal NPs. Hence, the irradiation is only used to deposit energy into the $\mathrm{SiO}_{2}-\mathrm{Au}$ layers. The values of the linear energy deposition rate into the electronic subsystem of the solid, i.e., the electronic stopping power, are 5.4, 6.7, and $9.7 \mathrm{keV} / \mathrm{nm}$ in $\mathrm{SiO}_{2}$ and 11, 14, and $24 \mathrm{keV} / \mathrm{nm}$ in gold for irradiations with $18 \mathrm{MeV} \mathrm{Ag}^{+4}, 25$ $\mathrm{MeV} \mathrm{Ag}{ }^{+5}$, and $54 \mathrm{MeV} \mathrm{Ag}^{+8}$, respectively. The characteristics of the samples and the irradiation conditions are summarized in Tables I and II.

The samples have been analyzed by using Rutherford backscattering spectrometry (RBS) and cross-sectional transmission electron microscopy (X-TEM). RBS analysis was performed with a beam of $2 \mathrm{MeV}^{4} \mathrm{He}^{+}$, at normal incidence, applying simultaneously two detectors at scattering angles of $170^{\circ}$ and $120^{\circ}$. Here we report the results obtained with the detector at the $120^{\circ}$ scattering angle, which has a better depth resolution, but the results obtained from the detector at $170^{\circ}$ are essentially the same. Samples prepared in cross-section (X-TEM) geometry were analyzed in a $300 \mathrm{keV}$ Philips CM30 microscope. TEM micrographs were processed with a slow scan charge coupled device camera and analyzed with the digital micrograph program. Although a precise measure of the elongation of the NPs can only be obtained from TEM analysis, an alternative and faster way to obtain the same information is to follow the broadening of the RBS peak with the fluence. In fact, as the gold peak designates the depth distribution of the metal species, its full width at half maximum (FWHM) gives a qualitative estimation of the extent of the elongation of the NPs. However, it is worth mentioning that this correspondence is only valid when the vast majority of gold atoms remain confined within their NP. Furthermore, the exact size cannot be extracted reliably from the RBS analysis; i.e., only the qualitative trend can be followed. Therefore, the results obtained from the RBS spectra have been compared to those deduced from the TEM micrographs whenever necessary to warrant the internal consistence of our experimental data sets. In the present report, we have always found a good agreement between the two techniques. Therefore, in the following the RBS and TEM results have been used in parallel to obtain insights into the ion-shaping phenomenon.

\section{RESULTS}

The ion beam shaping of embedded metal NPs has been studied by varying the initial size of NPs, their surface density, and the energy of the impinging ions. For the sake of clarity, the presentation of the experimental results has been organized in two subsections. In the first one we present the elongation as a function of the initial NP size and the ion beam energy. In the second subsection the dependence of the elongation process on the initial NP sizes and their initial concentrations is described.

\section{A. Elongation as a function of the initial NP size and the ion beam energy}

As we have mentioned above, the lengthening of the initially spherical NPs can be tracked by measuring the broadening of the Au peak width in the RBS spectra. Figures 3(a)-3(c) show the evolution of the Au peak with fluence of $15 \mathrm{~nm} \mathrm{Au} \mathrm{NPs} \mathrm{for} \mathrm{three} \mathrm{different} \mathrm{energies} \mathrm{of} \mathrm{the} \mathrm{impinging}$ Ag ions, viz., 18, 25, and $54 \mathrm{MeV}$. The sharp peak in the nonirradiated sample corresponds to a plane containing 15 $\mathrm{nm}$ particles, which are embedded in a silica matrix at a depth of approximately $150 \mathrm{~nm}$ below the surface. With increasing Ag ion fluence, the Au RBS peak broadens, indicating that the $\mathrm{Au}$ becomes distributed over a larger depth range. Thus, the relative increase in the peak width (FWHM) is taken as a measure for the increase in the dimension of the particle.

\section{Evolution of the $15 \mathrm{~nm}$ Au NPs as a function of irradiation energy}

Three identically prepared samples containing $15 \mathrm{~nm} \mathrm{Au}$ NPs with an average in-plane density of about 1.7 $\times 10^{10}$ particles $/ \mathrm{cm}^{2}$ have been irradiated with 18,25 , and $54 \mathrm{MeV}$ Ag swift heavy ions, respectively (see Fig. 4).

From the inspection of this figure, it can be deduced (i) that at an energy of $18 \mathrm{MeV}$, no deformation can be detected for fluences lower than $\sim 5.0 \times 10^{13}$ ions $/ \mathrm{cm}^{2}$ and that (ii) the Au RBS peak width reaches saturation for a fluence of $\sim(6-8) \times 10^{14}$ ions $/ \mathrm{cm}^{2}$. The X-TEM micrograph shown in Fig. 5(a) corresponds to our highest irradiation fluence (8.7 $\times 10^{14}$ ions $/ \mathrm{cm}^{2}$ ). It appears that the originally spherical NPs have been shaped into prolate nanorods with a length of $\sim 40 \mathrm{~nm}$ and a width of $\sim 8 \mathrm{~nm}$, corresponding to an aspect ratio of about 5 . The volume of these nanorods corresponds approximately to that of the pristine spherical NPs, i.e., $V_{\mathrm{NR}} \sim V_{\mathrm{NP}}$. This indicates that, at least for these irradiation conditions, the ion-shaping process is an individual process; i.e., each NP deforms into an individual prolate nanorod. We will see in Sec. III A 2 that at higher fluences this may no longer be the case.

The FWHM of the RBS Au peak after irradiating the sample with $25 \mathrm{MeV} \mathrm{Ag}{ }^{+5}$ ions is represented in Fig. 4. As for the irradiation with $18 \mathrm{MeV} \mathrm{Ag}$ ions, a threshold and a saturation fluence for deformation are observed at 3.0 $\times 10^{13}$ and $4.5 \times 10^{14}$ ions $/ \mathrm{cm}^{2}$, respectively. These fluences 


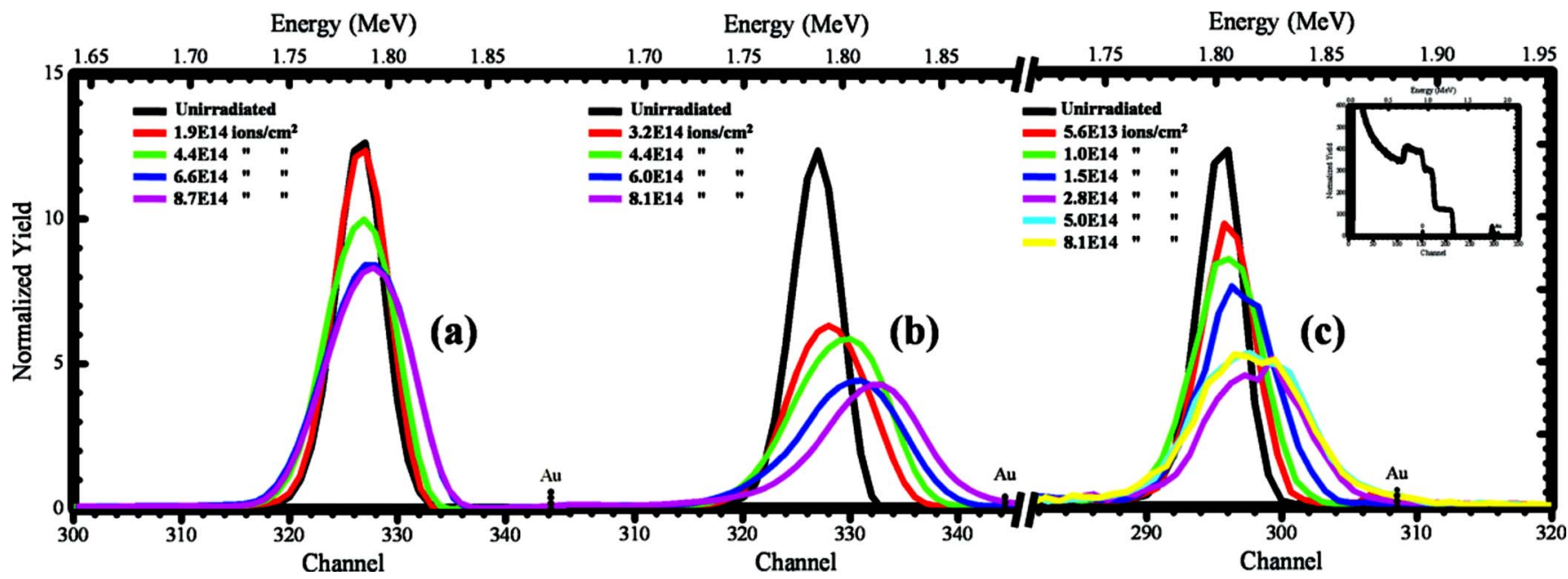

FIG. 3. (Color online) Normalized RBS spectra of $15 \mathrm{~nm} \mathrm{Au}$ particles under (a) $18 \mathrm{MeV} \mathrm{Ag}{ }^{+4}$ ions, (b) $25 \mathrm{MeV} \mathrm{Ag}^{+5}$ ions, and (c) $54 \mathrm{MeV}^{\mathrm{Ag}} \mathrm{g}^{+8}$ ions for samples prepared with an average concentration of $1.7 \times 10^{10}$ particles $/ \mathrm{cm}^{2}$. The surface channel of Au is indicated for each irradiation. Normalization of spectra is indicated in the inset of plot (c). Difference in energy-channel conversion in plot (c) is attributed to different experimental conditions than in plots (a) and (b).

are lower than the corresponding ones obtained for the 18 $\mathrm{MeV}$ irradiation. Finally, in the $54 \mathrm{MeV} \mathrm{Ag}$ ion irradiations the Au peak width broadens with increasing fluence until saturation is reached at a fluence of about 5.0 $\times 10^{14}$ ions $/ \mathrm{cm}^{2}$.

\section{Evolution of the $30 \mathrm{~nm}$ Au NPs as a function of irradiation energy}

A set of three identically prepared samples containing 30 $\mathrm{nm} \mathrm{Au} \mathrm{NPs} \mathrm{with} \mathrm{an} \mathrm{in-plane} \mathrm{density} \mathrm{of} \mathrm{about} 2.8$ $\times 10^{9}$ particles $/ \mathrm{cm}^{2}$ was irradiated with 18,25 , and $54 \mathrm{MeV}$ Ag swift heavy ions, respectively. Figure 6 shows the evolution of the FWHM of the Au peak derived from the RBS spectra for the different energies of the impinging ions.

During the irradiation with $18 \mathrm{MeV} \mathrm{Ag}$ ions, the FWHM of the RBS peak increases only slightly with fluence. An elongation threshold fluence of about $7.0 \times 10^{13}$ ions $/ \mathrm{cm}^{2}$ is deduced. However, as the increase in the width of the $\mathrm{Au}$ peak does not appear to be very large, it is possible that the energy deposited by the $18 \mathrm{MeV} \mathrm{Ag}$ ions into the electronic

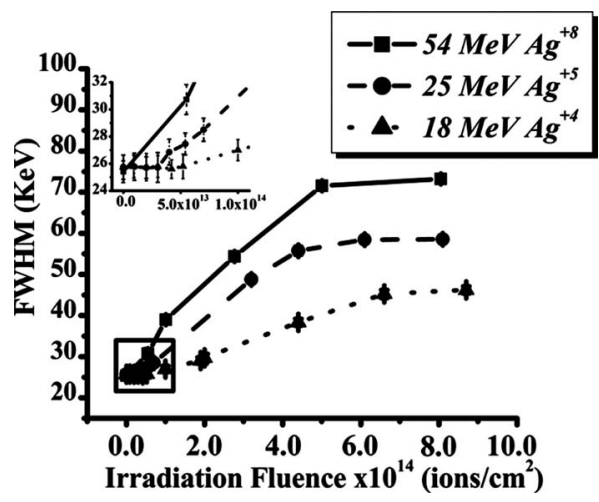

FIG. 4. The relative change of Au peak width as function of fluence for 15 $\mathrm{nm}$ Au particles under irradiation with $18 \mathrm{MeV} \mathrm{Ag}^{+4}$ ions (filled triangles and dot line), $25 \mathrm{MeV} \mathrm{Ag}^{+5}$ ions (filled circles and dash line), and $54 \mathrm{MeV}$ $\mathrm{Ag}^{+8}$ ions (filled squares and solid line). The inset represents a zoom-in of the region selected by the black square in the main figure. system approaches a threshold energy that must be reached before $30 \mathrm{~nm} \mathrm{Au}$ particles can be elongated substantially. This result is confirmed by the TEM analysis (not shown here). As the deformation is clearly observed when $15 \mathrm{~nm}$ NPs are irradiated at the same ion energy $(18 \mathrm{MeV})$, the swift heavy-ion-shaping mechanism is somehow dependent on the initial NP size.

For irradiation with $25 \mathrm{MeV} \mathrm{Ag}$ ions, the RBS peak starts to broaden at about $5.0 \times 10^{13}$ ions $/ \mathrm{cm}^{2}$, and saturation is observed above a fluence of $2.5 \times 10^{14}$ ions $/ \mathrm{cm}^{2}$.

Finally, for irradiation with $54 \mathrm{MeV} \mathrm{Ag}$ ions, the shaping of the NPs starts without any detectable threshold fluence
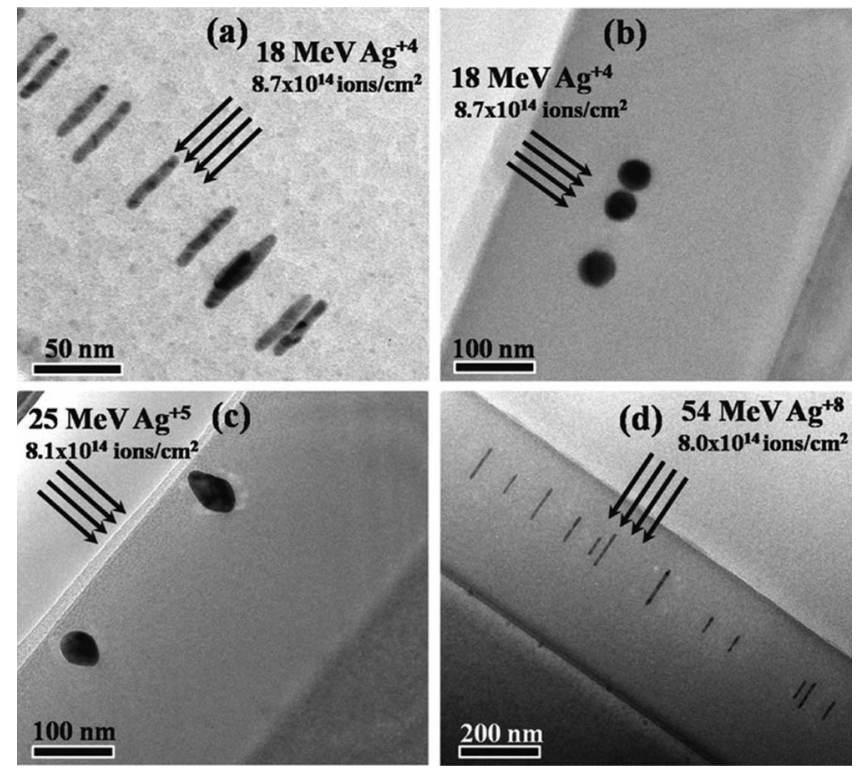

FIG. 5. X-TEM images of (a) $15 \mathrm{~nm}$ Au NPs irradiated with $18 \mathrm{MeV} \mathrm{Ag}^{+4}$ ions at a fluence of $8.7 \times 10^{14}$ ions $/ \mathrm{cm}^{2}$, (b) $45 \mathrm{~nm} \mathrm{Au} \mathrm{NPs} \mathrm{irradiated} \mathrm{with}$ $18 \mathrm{MeV} \mathrm{Ag}{ }^{+4}$ ions at a fluence of $8.7 \times 10^{14}$ ions $/ \mathrm{cm}^{2}$, (c) $45 \mathrm{~nm} \mathrm{Au} \mathrm{NPs}$ irradiated with $25 \mathrm{MeV} \mathrm{Ag}^{+5}$ at a fluence of $8.1 \times 10^{14}$ ions $/ \mathrm{cm}^{2}$, and (d) 15 $\mathrm{nm} \mathrm{Au} \mathrm{NPs} \mathrm{(lower} \mathrm{concentration)} \mathrm{irradiated} \mathrm{with} 54 \mathrm{MeV} \mathrm{Ag}^{+8}$ ions at a fluence of $8.0 \times 10^{14}$ ions $/ \mathrm{cm}^{2}$. The black arrows represent the direction of the ion beam. 


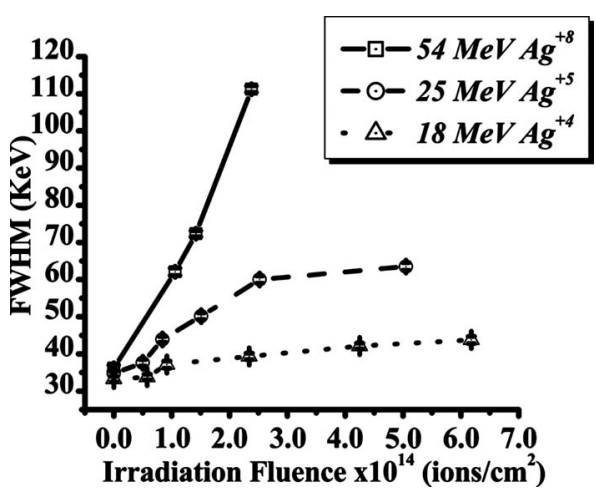

FIG. 6. The relative change in Au peak width as a function of fluence for 30 $\mathrm{nm}$ Au particles irradiated with $18 \mathrm{MeV} \mathrm{Ag}^{+4}$ ions (dot triangles and dot line), $25 \mathrm{MeV} \mathrm{Ag}{ }^{+5}$ ions (dot circles and dash line), and $54 \mathrm{MeV} \mathrm{Ag}^{+8}$ ions (dot squares and solid line). The in-plane density of Au NPs is about 2.8 $\times 10^{9}$ particles $/ \mathrm{cm}^{2}$.

and with a very large deformation rate. At the same time there is no indication for saturation over the entire fluence range up to $2.0 \times 10^{14}$ ions $/ \mathrm{cm}^{2}$.

\section{Evolution of the $45 \mathrm{~nm}$ Au NPs as a function of irradiation energy}

Three samples containing $45 \mathrm{~nm}$ Au NPs were irradiated with 18,25 , and $54 \mathrm{MeV} \mathrm{Ag}$ ions. The samples were prepared identically with an in-plane density of about 1.0 $\times 10^{9}$ particles $/ \mathrm{cm}^{2}$.

In Fig. 7, the evolution of the FWHM of the Au peak in the RBS spectra has been plotted as a function of the irradiation fluence. No measurable change in the Au peak width was observed for the irradiation with $18 \mathrm{MeV} \mathrm{Ag}^{+4}$ ions over the entire range of fluences investigated. This observation is confirmed by the X-TEM micrograph corresponding to the highest irradiation fluence, i.e., $8.7 \times 10^{14}$ ions $/ \mathrm{cm}^{2}$ [Fig. $5(\mathrm{~b})]$.

For the sample irradiated with $25 \mathrm{MeV} \mathrm{Ag}^{+5}$ ions, a broadening of the width of the Au peak is observed above a threshold fluence of $4.4 \times 10^{14}$ ions $/ \mathrm{cm}^{2}$. On the other hand, no saturation is observed up to a fluence of 8.1 $\times 10^{14}$ ions $/ \mathrm{cm}^{2}$. The corresponding X-TEM micrograph [Fig. 5(c)] shows a slight elongation of the NP in the direction parallel to the beam direction. Increasing the applied

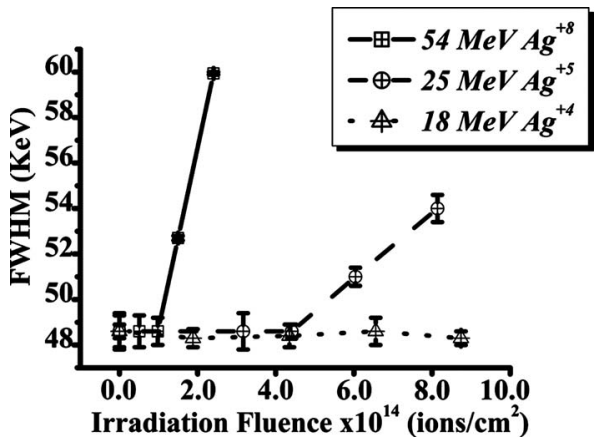

FIG. 7. The relative change in Au peak width as a function of fluence for 45

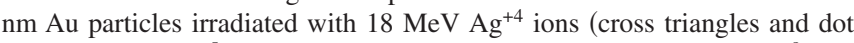
line), $25 \mathrm{MeV} \mathrm{Ag}^{+5}$ ions (cross circles and dash line), and $54 \mathrm{MeV} \mathrm{Ag}^{+8}$ ions (cross squares and solid line). The in-plane density of Au NPs is about $1.0 \times 10^{9}$ particles $/ \mathrm{cm}^{2}$.

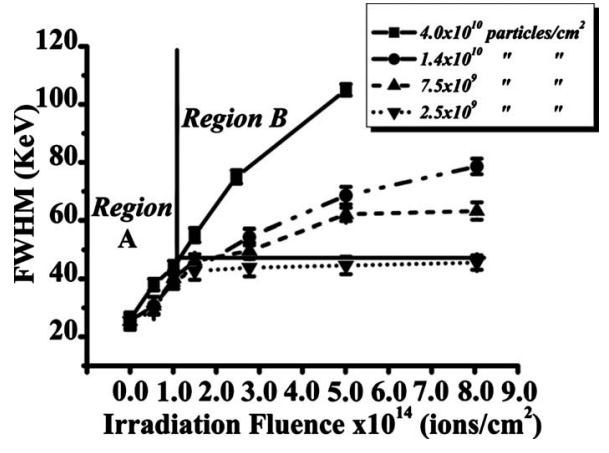

FIG. 8. The relative change of $15 \mathrm{~nm}$ Au peak width with irradiation fluence for different concentrations of Au NPs irradiated with $54 \mathrm{MeV} \mathrm{Ag}^{+8}$ ions. The inspection of the figure clearly reveals the existence of two regions: In region $\mathrm{A}$, NPs elongate irrespective of their initial concentration. In region $\mathrm{B}$, deformation effect increases with increasing the initial NP in-plane density.

swift heavy ion (SHI) irradiation energy to $54 \mathrm{MeV} \mathrm{Ag}^{+8}$ resulted in a reduction of the threshold fluence to 1.0 $\times 10^{14}$ ions $/ \mathrm{cm}^{2}$. Just like for the irradiation of $30 \mathrm{~nm} \mathrm{NPs}$ at the same SHI energy, no saturation is observed up to a fluence of $2.4 \times 10^{14}$ ions $/ \mathrm{cm}^{2}$.

To summarize, in this section we have shown that in the swift heavy-ion-shaping process both the initial NP size and the energy of the ion beam play a role. In particular, we demonstrate the existence of a threshold fluence for elongation, $\Phi_{c}$. This threshold fluence decreases with increasing ion energy and increases with the NP size. On the other hand, the existence of a saturation fluence for the elongation process has been observed for the 15 and $30 \mathrm{~nm}$ NPs but not for the $45 \mathrm{~nm}$ NPs. We have also shown that $45 \mathrm{~nm}$ NPs are not deformed when irradiated with $18 \mathrm{MeV} \mathrm{Ag}$ ions. This implies the existence of a threshold energy for deformation, which depends on the NP size; i.e., larger particles require higher ion beam energy or higher stopping power to be deformed.

\section{B. Elongation as a function of the NP concentration}

As shown in Fig. 1, the good uniformity of the in-plane NP density distribution and the absence of agglomeration, i.e., clustering of individual NPs together, enable us to investigate the influence of the interparticle distance on the ionshaping mechanism. Thus, in this subsection we will focus on this influence of the interparticle distance on the elongation phenomenon by varying the initial concentration of the NPs. As in Sec. III A, we consider three different NP sizes $(15,30$, and $45 \mathrm{~nm})$. The samples were irradiated at an ion energy of $54 \mathrm{MeV} \mathrm{Ag}^{+8}$.

\section{Evolution of the $15 \mathrm{~nm}$ Au NPs irradiated with 54 $\mathrm{MeV} \mathrm{Ag}^{+8}$ ions as a function of their interparticle distance}

Samples containing $15 \mathrm{~nm}$ NPs with in-plane densities ranging between $0.25 \times 10^{10}$ and $4.0 \times 10^{10}$ particles $/ \mathrm{cm}^{2}$ were irradiated with $54 \mathrm{MeV} \mathrm{Ag}{ }^{+8}$ ions up to a fluence of $8.0 \times 10^{14}$ ions $/ \mathrm{cm}^{2}$. Figure 8 shows the evolution of the FWHM of the RBS Au peak as a function of the NP concentration. The inspection of the figure clearly reveals the exis- 
tence of two regions: (i) For low irradiation fluences, the relative broadening of the RBS peak is almost equal for all the concentrations. We label this region as region A. (ii) Above a critical fluence of about $(1-2) \times 10^{14}$ ions $/ \mathrm{cm}^{2}$, the influence of the initial NP concentration on the broadening of the RBS peak becomes significant. In Fig. 8, this region has been labeled as region $\mathrm{B}$. Here the curves corresponding to initial NP concentrations of about $0.25,0.75$, and 1.4 $\times 10^{10}$ particles $/ \mathrm{cm}^{2}$ (grafting times of 5, 10, and $20 \mathrm{~min}$ ) evidence an evolution toward a saturation value. On the other hand, for an initial NP concentration of about 4.0 $\times 10^{10}$ particles $/ \mathrm{cm}^{2}$ (with a grafting time of $40 \mathrm{~min}$ ) the corresponding elongation curve does not exhibit a clear saturation effect. However, a slowing down of the deformation kinetics is observed for fluences larger than 2.5 $\times 10^{14}$ ions $/ \mathrm{cm}^{2}$. From these observations we can infer that the larger the initial NP concentration is, the larger the saturation values of the FWHM, i.e., the deformation effect, will be.

We assume that in region $\mathrm{A} \mathrm{Au} \mathrm{NPs} \mathrm{elongate} \mathrm{into} \mathrm{nano-}$ rods, keeping their original volume under irradiation, i.e., $V_{\mathrm{NR}} \sim V_{\mathrm{NP}}$. This is confirmed by X-TEM analysis [the results are analogous to those observed in Fig. 5(a) for an irradiation with $18 \mathrm{MeV}$ ions].

To understand the dependence of the FWHM of the RBS $\mathrm{Au}$ peak on the initial NP concentration observed in region $\mathrm{B}$, we refer to the TEM analysis for two extreme NP concentrations. First, we consider the TEM micrograph corresponding to the lowest NP concentration at a fluence of 8.0 $\times 10^{14}$ ions $/ \mathrm{cm}^{2}$, i.e., the last data point on the lowest curve in Fig. 8. The corresponding micrograph is shown in Fig. 5(d). It shows aligned $\mathrm{Au}$ nanorods with a major axis of about $85 \mathrm{~nm}$ long and a minor axis of about $8 \mathrm{~nm}$. A simple calculation reveals that the volume of the nanorods is about twice the volume of the initial NPs, i.e., $V_{\mathrm{NR}} \sim 2 V_{\mathrm{NP}}$. Let us next consider the TEM micrograph corresponding to the highest NP concentration and a fluence of 5.0 $\times 10^{14}$ ions $/ \mathrm{cm}^{2}$, i.e., the last data point of the highest curve in Fig. 8. The micrograph is reproduced in Fig. 11(a), which shows long nanowires whose major axes vary between 150 and $180 \mathrm{~nm}$. In this case, the volume of the longer nanowires is approximately five to six times that of the original NPs, i.e., $V_{\mathrm{NR}} \sim(5-6) V_{\mathrm{NP}}$. At the same time, we observe smaller aligned particles, which most likely result from the fragmentation of some of the ion-deformed nanowires.

\section{Evolution of the $30 \mathrm{~nm}$ Au NPs irradiated with 54 $\mathrm{MeV} \mathrm{Ag}^{+8}$ ions as a function of their interparticle distance}

$\mathrm{Au}$ NPs having a mean diameter of about $30 \mathrm{~nm}$ and an in-plane density ranging between $0.9 \times 10^{9}$ and 3.2 $\times 10^{9}$ particles $/ \mathrm{cm}^{2}$ were irradiated with $54 \mathrm{MeV} \mathrm{Ag}^{+8}$ ions up to a fluence of $5.0 \times 10^{14} \mathrm{ions} / \mathrm{cm}^{2}$. The evolution of the FWHM of the RBS Au peak with fluence for each NP concentration is shown in Fig. 9. As for the $15 \mathrm{~nm}$ NPs, we can observe again the existence of two separated regions. In the low-fluence region $\mathrm{A}$, the broadening of the RBS peak is independent of the initial particle concentration. On the other hand, for fluences larger than $1.0 \times 10^{14} \mathrm{ions} / \mathrm{cm}^{2}$, which

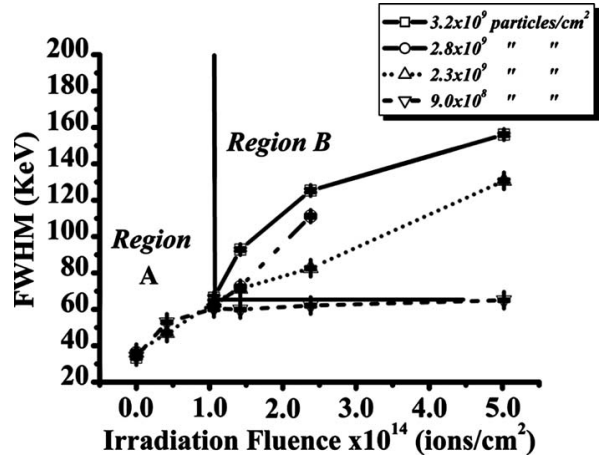

FIG. 9. The relative change for $30 \mathrm{~nm} \mathrm{Au}$ peak width with fluence for different concentrations of the Au NPs irradiated with $54 \mathrm{MeV} \mathrm{Ag}^{+8}$ ions. In region A, NPs elongate irrespective of their initial concentration. In region $\mathrm{B}$, deformation effect increases with increasing the initial NP in-plane density.

correspond to region $\mathrm{B}$, the width of the Au depth distribution increases with increasing in-plane Au NP density. The corresponding TEM micrographs in Figs. 11(c) and 11(d) show aligned $\mathrm{Au}$ nanowires with a length of about $\sim 200 \mathrm{~nm}$. These nanowires correspond to the last data point on the solid line in Fig. 9, i.e., to the highest NP concentration and a fluence of $5.0 \times 10^{14} \mathrm{ions} / \mathrm{cm}^{2}$.

\section{Evolution of the $45 \mathrm{~nm}$ Au NPs irradiated with 54 $\mathrm{MeV} \mathrm{Ag}^{+8}$ ions as a function of their interparticle distance}

Two samples of $45 \mathrm{~nm}$ diameter particles with in-plane densities of approximately $4.5 \times 10^{8}$ and 1.0 $\times 10^{9}$ particles $/ \mathrm{cm}^{2}$ have been irradiated with $54 \mathrm{MeV} \mathrm{Ag}^{+8}$ ions (Fig. 10). No significant change in the width of the RBS $\mathrm{Au}$ peak is observed as a result of the irradiations up to a fluence of $1.0 \times 10^{14} \mathrm{ions} / \mathrm{cm}^{2}$. Up to a fluence of 2.4 $\times 10^{14}$ ions $/ \mathrm{cm}^{2}$, the deformation rate appears to follow more or less the same evolution for the two concentrations considered.

To summarize, in this subsection we have shown that two regimes exist in the behavior of the ion deformation of the embedded Au NPs. Below a critical fluence (region A), all the NPs elongate irrespective of their initial concentration. Above this critical fluence (region B), the deformation effect increases with increasing initial NP concentration. For

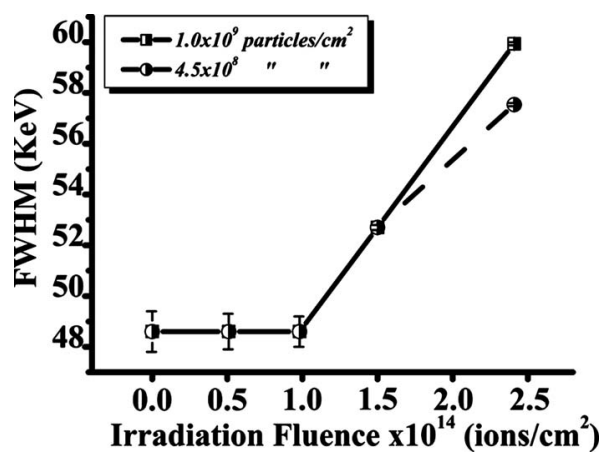

FIG. 10. The relative change in Au peak width for $45 \mathrm{~nm} \mathrm{Au}$ particles irradiated with $54 \mathrm{MeV} \mathrm{Ag}^{+8}$ ions at increasing fluences for two sample concentrations: $4.5 \times 10^{8}$ particles $/ \mathrm{cm}^{2}$ (half-filled circles and dash line) and $1.0 \times 10^{9}$ particles $/ \mathrm{cm}^{2}$ (half-filled squares and solid line). 
TABLE III. The threshold fluence for Au NP elongation as a function of ion energy and NP size.

\begin{tabular}{lcc}
\hline \hline Energy & $\begin{array}{c}\text { NP size } \\
(\mathrm{nm})\end{array}$ & $\begin{array}{c}\text { Threshold fluence } \\
\left(\text { ions } / \mathrm{cm}^{2}\right)\end{array}$ \\
\hline $18 \mathrm{MeV} \mathrm{Ag}{ }^{+4}$ & 15 & $5 \times 10^{13}$ \\
$25 \mathrm{MeV} \mathrm{Ag}^{+5}$ & & $3 \times 10^{13}$ \\
$18 \mathrm{MeV} \mathrm{Ag}^{+4}$ & 30 & $7 \times 10^{13}$ \\
$25 \mathrm{MeV} \mathrm{Ag}^{+5}$ & & $5 \times 10^{13}$ \\
& & $\ldots$ \\
$18 \mathrm{MeV} \mathrm{Ag}^{+4}$ & 45 & $4 \times 10^{14}$ \\
$25 \mathrm{MeV} \mathrm{Ag}^{+5}$ & & $1 \times 10^{14}$ \\
$54 \mathrm{MeV} \mathrm{Ag}^{+8}$ & & \\
\hline \hline
\end{tabular}

the NP diameters of 15 and $30 \mathrm{~nm}$, the transformation from the region $\mathrm{A}$ to the region $\mathrm{B}$ occurs approximately in the same fluence range of $(1-2) \times 10^{14}$ ions $/ \mathrm{cm}^{2}$.

\section{DISCUSSION}

\section{A. Existence of a threshold fluence for elongation}

Systematic investigations of the deformation of NPs in response to SHI irradiation have allowed us to evidence experimentally the existence of a threshold fluence for elongation, $\Phi_{c}$. The value of $\Phi_{c}$ has been observed to depend on both ion energy and pristine NP size. In particular, $\Phi_{c}$ decreases with increasing electronic stopping power and in creases with the NP diameter (Table III). However, as suggested by Klaumünzer ${ }^{16}$ and successively experimentally shown by Penninkhof et al. ${ }^{14}$ and Penninkhof, ${ }^{15}$ irradiationinduced NP elongation is a complicated issue where both the matrix and the characteristics of the confined NPs play an active role. Here, we put forward three possible mechanisms that could intervene in the observed variation of $\Phi_{c}$ with ion energy and NP size: (i) sample preparation, (ii) silica compaction under irradiation, and (iii) irradiation-induced stresses that occur in a silica film when it is constrained by a substrate.

(i) As explained in the experimental section, Au NPs are first grafted at the surface of a thermally grown silica film and then confined within the matrix by successive sputtering of a second silica layer on top of the first one. As gold has a poor wetting affinity with $\mathrm{SiO}_{2}$, it is not precisely clear how the oxide layer forms around a NP in the sputtering deposition process. Since the $\mathrm{SiO}_{2}$ top film is deposited in the low adatom mobility, zone 1 , growth mode ${ }^{23}$ at a relatively low ion bombardment energy ${ }^{24}$ most likely voids are expected to form in the growing oxide near the lower half of the NP due to shadowing effects in the sputter deposition. Even though none of these voids were imaged during the TEM analysis [Fig. 5 (b)], it is conceivable that a certain compaction of the oxide is necessary before the deformation process can start.

(ii) When irradiated with swift heavy ions, a dielectric matrix exhibits a compaction of about $3 \%$ at low fluences and an anisotropic growth at high fluences. ${ }^{25-28}$
The densification of the silica is due to the rearrangement of the $\mathrm{SiO}_{2}$ ring network into smaller, more compact rings. ${ }^{29,30}$ In particular, for SHI irradiation, the density of the virgin material is irreversibly modified within each individual cylindrical ion track while a subsequent ion impact in the same region does not produce any further density changes. ${ }^{25}$ In this framework, the fluence necessary to complete the compaction corresponds roughly to a situation where all neighboring tracks show some mutual overlap, such that the perturbed area covers the whole sample surface.

(iii) Finally, our silica film is not freestanding, but it is constrained by a silicon substrate. The effect of the ion irradiation on the stress state of a constrained silica film has been intensively studied in the past. ${ }^{26-28}$ Depending on the irradiation fluence, two opposite stress situations have been measured: (i) at low fluences, ion irradiation causes the initially compressed stress to turn into a tensile one. This process, which is related to the compaction mechanism, leads the sample to a higher equilibrium density, which reaches its maximum value at the end of the matrix densification, i.e., for fluences up to few $10^{13}$ ions $/ \mathrm{cm}^{2}$. (ii) For larger irradiation fluences, i.e., fluences larger than $10^{14}$ ions $/ \mathrm{cm}^{2}$, the anisotropic deformation dominates the further evolution of the system. This effect is associated with the decrease in the tensile stress and the buildup of a compressive stress for the constrained film.

First, considering mechanisms (i) and (ii), we suggest that the NP deformation does not occur as long as the structural transformation of the silica matrix is not finished. Moreover, adopting this hypothesis we try to correlate the evolution of the deformation threshold with the energy of the impinging ions. As the end of silica compaction corresponds to the situation where the sample surface becomes completely covered by the mutually overlapping ion tracks, the corresponding threshold fluence will depend on the track diameter. In other words, the larger the track dimension is, the lower the threshold fluence will be. There are several publications containing data for track cross sections in silica, both experimental and theoretical. See, for example, Refs. 31-34. In the latter, the track size is deduced from the thermal spike model and corresponds to the region that melted in the wake of the passing swift heavy projectile. ${ }^{35}$ For the three ion energies $(18,25$, and $54 \mathrm{MeV} \mathrm{Ag})$ and the corresponding electronic stopping powers $(5.4,6.7$, and $9.7 \mathrm{keV} / \mathrm{nm}$ ) considered, the corresponding track diameters are approximately 3 , 4 , and $5 \mathrm{~nm}$, respectively. From these values, one can calculate that the complete overlap of the tracks at the sample surface takes place for fluences of $2.0 \times 10^{13}, 1.0 \times 10^{13}$, and $0.5 \times 10^{13}$ ions $/ \mathrm{cm}^{2}$, respectively. Considering that (i) the irradiation process follows random statistics and that (ii) for a silica matrix containing partially wetted metallic NP the compaction fluence can be different from that of pure silica 
film, our estimations account quite well for the observed reduction in the deformation threshold with increasing ion energy.

Besides, the analysis of the RBS data shows that the inertia against deformation increases with NP size. In other words, larger NPs require larger electronic stopping powers to be deformed. As the macroscopic stress generated from SHI irradiation in planar constrained films can reach values as large as several hundreds of megapascal, we suggest that mechanism (iii) can participate to the evolution of the NPs. It should be mentioned that this scenario has already been proposed by Roorda et al. ${ }^{13}$ to explain the shape change of $\mathrm{Au}$ NPs that are confined within a silica shell and assumed to be solid. However, as pointed out by Klaumünzer, ${ }^{16}$ this indirect mechanism alone is not sufficient to account for the observed deformation of solid NPs; i.e., the metallic NP must actively participate in the deformation process. In other words, elongation will only occur when the temperatures of both the metallic NP and the dielectric $\mathrm{SiO}_{2}$ exceed their respective individual melting temperatures. ${ }^{16,36}$ It has been argued that the energy deposit corresponding to the electronic stopping power can melt metallic NPs whose diameters range between 6 and $20 \mathrm{~nm} .{ }^{5,17}$ On the other hand, larger particles are not expected to melt and are not observed to deform under SHI irradiation. ${ }^{5,9,16,17}$ For example Awazu et al. ${ }^{17}$ observed that $\mathrm{Au}$ NPs measuring over $50 \mathrm{~nm}$ do not deform under 110 $\mathrm{MeV} \mathrm{Br}$ ion irradiation at a fluence of $1.0 \times 10^{14} \mathrm{ions} / \mathrm{cm}^{2}$. However, it is conceivable that within this class of NP sizes, a minimum compressive stress is required to activate the deformation of the NPs. It worth mentioning that this threshold stress (or minimum fluence) cannot be uniquely ascribed to the stress generated by the individual ion track ${ }^{37-39}$ because the deformation threshold would then only depend on the electronic energy loss. Hence, a macroscopic stress has to be invoked to explain the observations. In this sense, the larger the NP is, the larger the minimum compressive stress necessary to trigger the deformation process will have to be, and thus the larger the fluence necessary to reach it will have to be as well. This hypothesis qualitatively accounts for our experimental observations that the onset of the deformation depends on ion energy, NP size, and irradiation fluence.

\section{B. Dependence of the elongation on the NP concentration}

Two distinct regimes have been observed for the elongation of metal NPs as a function of their initial concentration: (i) For low irradiation fluences, Au NPs deform into ionaligned nanorods. This transformation of the morphology occurs in a regime of conservation of volume. In other words, the ion shaping is an individual mechanism, whereby each pristine NP deforms into a single prolate nanorod. As this behavior is observed for all NP concentrations, in this first stage the ion shaping can be seen as an individual process from the viewpoint of the NPs. (ii) For larger irradiation fluences, i.e., above $1.0 \times 10^{14}$ ions $/ \mathrm{cm}^{2}$, RBS analysis indicates that the deformation rate is very sensitive to the initial NP concentration. In particular, the deformation rate increases with the increase in the initial NP concentration. In this second stage, TEM micrographs show the formation of
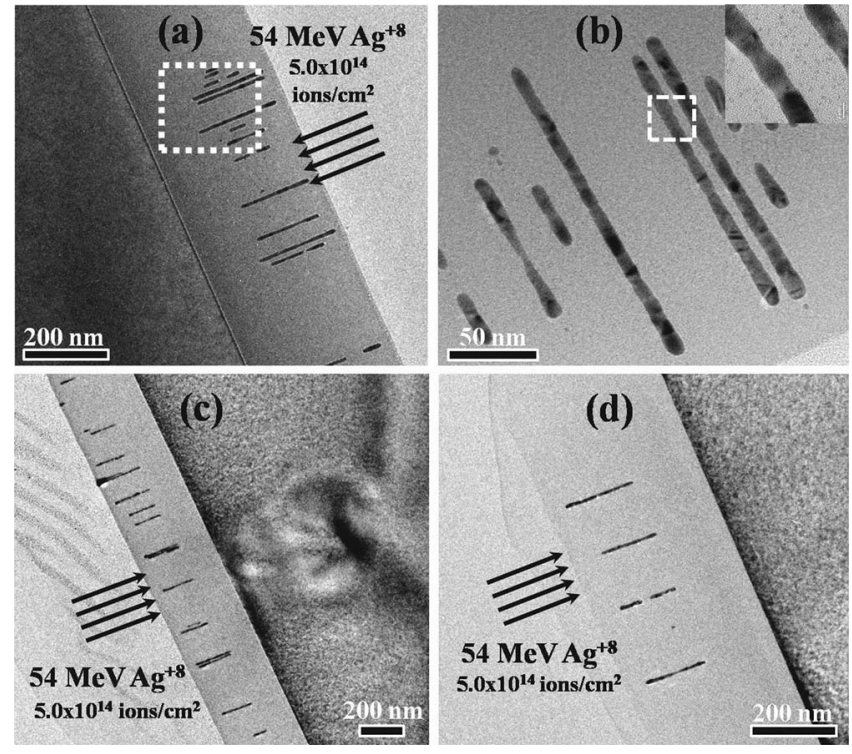

FIG. 11. [(a) and (b)] X-TEM images of $15 \mathrm{~nm}$ Au NPs (in-plane density of $4.0 \times 10^{10}$ particles $/ \mathrm{cm}^{2}$ ) irradiated with $54 \mathrm{MeV} \mathrm{Ag}{ }^{+8}$ ions at a fluence of $5.0 \times 10^{14}$ ions $/ \mathrm{cm}^{2}$. [(c) and (d)] X-TEM images of $30 \mathrm{~nm} \mathrm{Au} \mathrm{NPs} \mathrm{(in-}$ plane density of $3.2 \times 10^{9}$ particles $/ \mathrm{cm}^{2}$ ) irradiated with $54 \mathrm{MeV} \mathrm{Ag}^{+8}$ ions at a fluence of $5.0 \times 10^{14}$ ions $/ \mathrm{cm}^{2}$.

long nanowires accompanied by a disintegration, or a fragmentation, of some of the Au NPs. For the longest nanowires, the ratio between their volumes to that of the spherical unirradiated NPs ranges between 4 and 6 (considering both NP sizes of 15 and $30 \mathrm{~nm}$ ). This means that the elongation process necessitates the contributions coming from several individual NPs. Thus, above a critical fluence the ion shaping becomes a collective process whereby some of the NPs, or even some of the nanowires, disappear under the irradiation, while others continue to grow by incorporating metal atoms from the disappearing particles.

The mechanism governing the growth of the long nanowires is most likely related to mass transport through the silica matrix in the form of diffusion of gold solute from the dissolved/fragmented NPs toward the stable NPs. Some insights can be obtained from Fig. 11(b), and the corresponding inset, where tiny satellite particles surrounding the nanowires are clearly visible. As these small particles were not observed in the pristine samples, they must come into existence during the ion-NP interaction. It means that the energy deposited into, or eventually close to, the NP subsystem allows the gold atoms to be put into solution. The supersaturated solid solution may then evolve toward the precipitation of a second phase (the satellite particles) due to local fluctuations of the solute concentration. As these small precipitates are unstable against swift heavy-ion irradiation, they are dissolved by subsequent impinging ions, allowing the metal species to diffuse through the silica matrix; i.e., the diffusion is triggered by the creation of a transient melted region formed in the wake of the impinging ions. Supporting this idea is the direct observation of gold diffusion within ion tracks reported by Dais et $a l .{ }^{40}$ As this process depends on the amount of the solute sources available, i.e., the NP concentration, the lower their relative distance the shorter the diffusion time and the longer the nanowires, as shown in Fig. 
8. On the other hand, when the NP concentration is low, the particle growth becomes limited by the distance between the particles, which is too long. This effect accounts for the relatively low saturation length observed in the samples having the lowest NP concentration. If the metal solute can only diffuse within the thermal spike region, then for each ion impact the diffusion distance will be proportional to the track diameter. In our case this value ranges between 3 and $5 \mathrm{~nm}$ depending on the ion energy. Taking the minimum average distance among the NPs, which is about $50 \mathrm{~nm}$, and assuming that the fluence necessary for the complete overlap of the sample surface is of the order of $1.0 \times 10^{13}$ ions $/ \mathrm{cm}^{2}$, at least ten ion impacts are statistically necessary to diffuse over $50 \mathrm{~nm}$. This corresponds to a minimum fluence of about $1.0 \times 10^{14} \mathrm{ions} / \mathrm{cm}^{2}$ for solute metal atoms to diffuse from one particle to the nearest one. Experimentally this matches with the fluence necessary to pass from regime I (individual deformation) to regime II (collective deformation process).

\section{CONCLUSIONS}

In conclusion, we have shown that the shape of spherical $\mathrm{Au}$ NPs embedded within a $\mathrm{SiO}_{2}$ matrix can be modified by irradiation with Ag swift heavy ions. We have reported the existence of threshold fluence for deformation, and we have investigated its extent by varying both NP size and ion energy. Finally, we show that the size and concentration of $\mathrm{Au}$ NPs have a decisive influence on the irradiation-induced deformation of confined NPs. Below a critical fluence (region A), all the NPs elongate irrespective of their initial concentration; i.e., the ion-shaping process is limited to the transformation of a single spherical NP into a single prolate nanorod. Above this critical fluence (region B), a collective mechanism is active, where several NPs participate to the growth of a single long nanowire. In this region, the deformation effect increases with increasing initial NP concentration; i.e., the higher the initial concentration of NPs, the longer the nanowires.

${ }^{1}$ J. M. Gerardy and M. Ausloos, Phys. Rev. B 25, 4204 (1982).

${ }^{2}$ J. J. Penninkhof, A. Polman, L. A., Sweatlock, S. A. Maier, H. A. Atwater, A. M. Vredenberg, and B. J. Kooi, Appl. Phys. Lett. 83, 4137 (2003).

${ }^{3}$ M. Quinten and U. Kreibig, Appl. Opt. 32, 6173 (1993).

${ }^{4}$ F. Gonella and P. Mazzoldi, Handbook of Nanostructured Materials and Nanotechnology (Academic, San Diego, 2000), Vol. 4.

${ }^{5}$ C. D’Orléans, J. P. Stoquert, C. Estournès, C. Cerruti, J. J. Grob, J. L. Guille, F. Haas, D. Muller, and M. Richard-Plouet, Phys. Rev. B 67, 220101 (2003).

${ }^{6}$ C. D'Orléans, J. P. Stoquert, C. Estournès, J. J. Grob, D. Muller, C. Cerruti, and F. Haas, Nucl. Instrum. Methods Phys. Res. B 225, 154 (2004).

C. D’Orléans, J. P. Stoquert, C. Estournès, J. J. Grob, D. Muller, J. L. Guille, M. Richard-Plouet, C. Cerruti, and F. Haas, Nucl. Instrum. Methods Phys. Res. B 216, 372 (2004).

${ }^{8}$ R. Giulian, P. Kluth, D. J. Sprouster, L. L. Araujo, A. Byrne, and M. C.
Ridgway, Nucl. Instrum. Methods Phys. Res. B 266, 3158 (2008).

${ }^{9}$ R. Giulian, P. Kluth, L. L. Araujo, D. J. Sprouster, A. P. Byrne, D. J. Cookson, and M. C. Ridgway, Phys. Rev. B 78, 125413 (2008).

${ }^{10}$ A. Oliver, J. A. Reyes-Esqueda, J. C. Cheang-Wong, C. E. RománVelázquez, A. Crespo-Sosa, L. Rodríguez-Fernández, J. A. Seman, and C. Noguez, Phys. Rev. B 74, 245425 (2006).

${ }^{11}$ J. J. Penninkhof, T. van Dillen, C. Graf, A. van Blaaderen, A. M. Vredenberg, and A. Polman, Nucl. Instrum. Methods Phys. Res. B 242, 523 (2006).

${ }^{12}$ Y. K. Mishra, F. Singh, D. K. Avasthi, J. C. Pivin, D. Malinovska, and E. Pippel, Appl. Phys. Lett. 91, 063103 (2007).

${ }^{13}$ S. Roorda, T. van Dillen, A. Polman, C. Graf, A. van Blaaderen, and B. J. Kooi, Adv. Mater. (Weinheim, Ger.) 16, 235 (2004).

${ }^{14}$ J. J. Penninkhof, C. Graf, T. Van Dillen, A. M. Vredenberg, A. Van Blaaderen, and A. Polman, Adv. Mater. (Weinheim, Ger.) 17, 1484 (2005).

${ }^{15}$ J. J. Penninkhof, Ph.D. thesis, Utrecht University, 2006.

${ }^{16}$ S. Klaumünzer, Nucl. Instrum. Methods Phys. Res. B 244, 1 (2006).

${ }^{17}$ K. Awazu, X. Wang, M. Fijimaki, and J. Tominga, Phys. Rev. B 78, 054102 (2008).

${ }^{18}$ E. S. Kooij, E. A. M. Brouwer, H. Wormeester, and B. Poelsema, Colloids Surf., A 222, 103 (2003).

${ }^{19}$ Z. Adamczyk, Adv. Colloid Interface Sci. 267, 100 (2003).

${ }^{20}$ L. M. Liz-Marzán, M. Giersig, and P. Mulvaney, Langmuir 12, 4329 (1996).

${ }^{21}$ G. Schmid and U. Simon, Chem. Commun. (Cambridge) 2005 (6), 697.

${ }^{22}$ J. F. Ziegler, J. P. Biersack, and M. D. Ziegler, SRIM, a version of the TRIM program, The Stopping and Range of Ions in Matter, 2008 (http:// www.srim.org).

${ }^{23}$ R. Messier, V. C. Venugopal, and P. D. Venul, J. Vac. Sci. Technol. A 18, 1538 (2000).

${ }^{24}$ E. D. van Hattum, A. Palmero, W. M. Arnoldbik, H. Rudolph, and F. H. P. M. Habraken, Appl. Phys. Lett. 91, 171501 (2007).

${ }^{25}$ A. Benyagoub, S. Klaumünzer, and M. Toulemonde, Nucl. Instrum. Methods Phys. Res. B 146, 449 (1998).

${ }^{26}$ E. Snoeks, T. Weber, A. Cacciato, and A. Polman, J. Appl. Phys. 78, 4723 (1995).

${ }^{27}$ M. L. Brongersma, E. Snoeks, T. van Dillen, and A. Polman, J. Appl. Phys. 88, 59 (2000).

${ }^{28}$ T. van Dillen, M. Y. S. Siem, and A. Polman, Appl. Phys. Lett. 85, 389 (2004).

${ }^{29}$ W. Primak, Studies in Radiation Effects in Solids (Gordon and Breach, New York, 1975), Vol. 4.

${ }^{30}$ R. A. B. Devine, Nucl. Instrum. Methods Phys. Res. B 91, 378 (1994).

${ }^{31}$ A. Meftah, F. Brisard, J. M. Constantini, E. Dooryhee, M. Hageali, M. Hervieu, J. P. Stoquert, F. Studer, and M. Toulemonde, Phys. Rev. B 49, 12457 (1994).

${ }^{32}$ A. Meftah, M. Djebara, N. Khalfaoui, and M. Toulemonde, Nucl. Instrum. Methods Phys. Res. B 146, 431 (1998).

${ }^{33}$ P. Kluth, C. S. Schnohr, D. J. Sprouster, A. P. Byrne, D. J. Cookson, and M. C. Ridgway, Nucl. Instrum. Methods Phys. Res. B 266, 2994 (2008).

${ }^{34}$ C. C. Rotaru, Ph.D. thesis, University of Caen, 2004 (http://tel.archivesouvertes.fr/tel-00005399).

${ }^{35}$ M. Toulemonde, C. Dufour, and E. Paumier, Phys. Rev. B 46, 14362 (1992).

${ }^{36}$ S. Klaumünzer, Nucl. Instrum. Methods Phys. Res. B 225, 136 (2004).

${ }^{37}$ H. Trinkaus and A. I. Ryazanov, Phys. Rev. Lett. 74, 5072 (1995).

${ }^{38}$ H. Trinkaus, Nucl. Instrum. Methods Phys. Res. B 146, 204 (1998).

${ }^{39}$ P. Kluth, C. S. Schnohr, O. H. Pakarinen, F. Djurabekova, D. J. Sprouster, R. Giulian, M. C. Ridgway, A. P. Byrne, C. Trautmann, D. J. Cookson, K. Nordlund, and M. Toulemonde, Phys. Rev. Lett. 101, 175503 (2008).

${ }^{40}$ C. Dais, T. Bolse, W. Bolse, P. Shubert-Bischoff, and J. N. K. Lindner, Nucl. Instrum. Methods Phys. Res. B 245, 239 (2006). 